\title{
In Vitro Cytotoxicity of Some Natural and Semi-Synthetic Isocoumarins from Paepalanthus bromelioides
}

\author{
Karina F. Devienne ${ }^{a}$, Maria Stella G. Raddi ${ }^{\text {,**, Eliana A. Varanda }}{ }^{\text {b }}$ \\ and Wagner Vilegas ${ }^{\text {a }}$ \\ a Instituto de Química de Araraquara, \\ b Faculdade de Ciências Farmacêuticas de Araraquara, Universidade Estadual Paulista \\ "Júlio de Mesquita Filho", Rodovia Araraquara-Jaú, $\mathrm{K}_{\mathrm{m}}$ 1, 14801-902, Araraquara, \\ SP, Brazil. Fax: (0055) 16 2320880. E-mail: raddims@fcfar.unesp.br \\ * Author for correspondence and reprint requests \\ Z. Naturforsch. 57c, 85-88 (2002); received August 3/September 10, 2001 \\ Paepalanthus bromelioides, Isocoumarin, Cytotoxicity Activity \\ Numerous natural compounds have a potential for therapeutic applications, but may have \\ to be chemically modified to alter toxic side effects. We investigated structural parameters \\ that could affect the cytotoxicity of isocoumarins similar to 9,10-dihydroxy-5,7-dimethoxy- \\ $1 H$-naphtho(2,3c)pyran-1-one (paepalantine 1). Paepalantine 1 has antimicrobial activity, as \\ well as significant in vitro cytotoxic effects in the McCoy cell line. Two other natural and two \\ semi-synthetic isocoumarins with similar structures obtained from the capitula of Paepalan- \\ thus bromelioides were tested on the same cell line by the neutral red assay. Substitution of \\ the 9 and/or 10-OH group made these compounds less cytotoxic.
}

\section{Introduction}

Numerous compounds with biological activity have been investigated, however many of them are not suitable for therapeutic use due to their toxic, carcinogenic and mutagenic properties. Nowadays, it is possible to make modifications of active chemical structures, in order to synthesize compounds with improved therapeutic activity and reduced toxicity.

Isocoumarins are secondary metabolites derived from the acetate pathway, and are structurally related to the coumarins, but with an inverted lactone ring (Hill, 1986). They are produced by microorganisms, insects and some higher plants, and have a wide range of biological activities, including: antitumoral, antileucemic, antiviral and antimicrobial (Hill, 1986; Cañedo et al., 1996; Whyte et al., 1996). Although some isocoumarins have beneficial properties, they also have been reported to be toxic for eukaryotic cells. An example is ochratoxin A, a potent mycotoxin produced by Aspergillus and Penicillium species, which is hepatotoxic, nephrotoxic, teratogenic and carcinogenic in animals (Zepnik et al., 2001).

Some isocoumarins have been isolated from species of the plant family Eriocaulaceae. This family is widespread in the region of the Serra do
Cipó, Minas Gerais state, Brazil. Paepalanthus is the largest genus of this family, with about 500 species, and more than 400 of these occur only in Brazil. The first isocoumarin isolated from $P$. bromelioides, 9,10-dihydroxy-5,7-dimethoxy- $H$-naphtho(2,3c)pyran-1-one, named paepalantine 1, was found to have antimicrobial activity, as well as significant cytotoxicity in McCoy cell line and in Chinese hamster ovary cells $\left(\mathrm{CHO}_{9}\right)$ (Varanda et al., 1997). Two other natural isocoumarins, paepalantine-9-O- $\beta$-D-glucopyranoside and paepalantine-9O- $\beta$-D-allopyranosyl $(1 \rightarrow 6)$ glucopyranoside were isolated from an ethanolic extract of this plant species, and their structure was determined by spectrometric analysis (Vilegas et al., 1998). The 9-OH10-methylated and 9,10-acylated derivative were semi-synthesized through methylation with diazomethane and acetylation with acetic anhydride/ pyridine, respectively (Vilegas et al., 1990).

Actually, in vitro cytotoxicity assays with cultured cells are widely used to chemicals including cancer chemotherapeutics, pharmaceuticals, biomaterials, natural toxins, antimicrobial agents and industrial chemicals because they are rapid and economical (Barile, 1994; Ishiyama et al., 1996). These cytotoxicity tests measure the concentration of the substance that damages components, structures or cellular biochemical pathways, and they 
also allow direct extrapolation of quantitative data to similar in vivo situations (Freshney, 1994; Balls and Clothier, 1992; Bacon et al., 1990).

The main objective of this investigation was to explore the structure-cytotoxicity relationships of some natural and semi-synthetic isocoumarins using the microculture neutral red assay.

\section{Materials and Methods}

\section{Test compounds}

The substances were obtained as described by Vilegas et al., 1990 and Vilegas et al., 1997 (Table I) and they were stored as stock solutions at $2.0 \mathrm{mg} /$ $\mathrm{ml}$ in DMSO. Eagle medium with various concentrations of DMSO was used in the experimental design. The final concentration of DMSO (4\%) used does not interfere cell viability. The purity of the compounds was proved by HPLC using column chromatography on $\mathrm{C}_{18}$ reversed phase and $\mathrm{ACN}-\mathrm{H}_{2} \mathrm{O}(70: 30 \mathrm{v} / \mathrm{v})$ as the eluting solvent.

\section{Reference substance}

Cisplatin, a cytotoxic substance used in antineoplasic therapy, was evaluated in the same cellular system to obtain cytotoxicity parameters, allowing us to classify the isocoumarins according to their relative toxicity.

\section{Experimental design}

McCoy mouse fibroblast cell line (ATCC CRL1696b) was maintained in Eagle medium with $7.5 \%$ fetal bovine serum. After trypsinization, $0.2 \mathrm{ml}$ aliquots of medium containing approximately $10^{4}$ cells $/ \mathrm{ml}$ were seeded into 96-well tissueculture plates and incubated at $37^{\circ} \mathrm{C}$. After $24 \mathrm{hr}$, the Eagle medium was removed and the cells were placed into unmodified medium (control) or in medium modified with various concentrations of test chemicals. After incubating for another $24 \mathrm{hr}$, the medium was removed and the plates were prepared for the neutral red (NR) assay. After brief agitation, the plates were transferred to a microplate reader (Spectra and Rainbow (Shell) Readers - Tecan, Austria) and the optical density of each well was measured using a $540 \mathrm{~nm}$ filter and a $620 \mathrm{~nm}$ reference wavelength (Borenfreund and Puerner, 1985). All experiments were performed at least four times, using three wells for each concentration of each chemical tested. The cytotoxicity data was standardized by determining absorbance and calculating the correspondent chemical concentrations. Linear regression analysis with 95\% confidence limit was used to define dose-response curves and to compute the concentration of chemical agents needed to reduce absorbance of the NR by $50 \%\left(\mathrm{IC}_{50}\right)$, the so called cytotoxic midpoint (Barile, 1994).

\section{Results and Discussion}

The isocoumarins are extremely variable in structure, due to the various types of substitutions in their basic structure, which can influence their biological activity (Hill, 1986). Varanda et al. (1997) and Tavares et al. (1999) suggest that alterations in the chemical structure of paepalantine 1 could change its cytotoxic properties. Relative cytotoxicity of isocoumarins for the McCoy cell line was: paepalantine 1 and 9,10-acylated derivative $>$ paepalantine $9-0-\beta$-D-glucopyranoside $>$ paepalantine $9-0-\beta$-D-allopyranosyl $(1 \rightarrow 6)$ glucopyranoside and it's 9-OH-10-methylated derivative (Table II).

The paepalantines analyzed in this study have different chemical groups at position 9 and/or 10 of the aromatic ring. It is noteworthy that substitu-

Table I. Chemical structures of natural and semi-synthetic isocoumarins.

\begin{tabular}{lccc}
\multicolumn{1}{c}{ Isocoumarins } & $\mathrm{R}_{1}$ & $\mathrm{R}_{2}$ \\
\hline $\begin{array}{l}\text { Paepalantine 1 } \\
\text { Paepalantine 9-0- } \beta \text {-D-glucopyranoside }\end{array}$ & $\mathrm{H}$ & $\mathrm{H}$ & $\mathrm{Hlc}$ \\
Paepalantine 9-0- $\beta$-D-allopyranosyl $(1 \rightarrow 6)$ glucopyranoside & $-\mathrm{glc} \underline{6}$ all & $\mathrm{H}$ \\
9,10-Acylated derivative & $\mathrm{Ac}$ & $\mathrm{Ac}$ \\
9-OH-10-Methylated derivative & $\mathrm{H}$ & $\mathrm{Me}$ &
\end{tabular}


Table II. Cytotoxicity of isocoumarins against McCoy cells using neutral red assay.

\begin{tabular}{ll}
\hline \multicolumn{1}{c}{ Isocoumarins } & $\mathrm{IC}_{50} *[\mu \mathrm{g} / \mathrm{ml}]$ \\
\hline Paepalantine 1 & $37.8 \pm 1.3$ \\
Paepalantine 9-0- $\beta$-D-glucopyranoside & $50.2 \pm 7.2$ \\
Paepalantine 9-0- $\beta$-D-allopyranosyl- & $52.1 \pm 7.5$ \\
$(1 \rightarrow 6$ )glucopyranoside & $43.3 \pm 1.3$ \\
9,10-Acylated derivative & $62.7 \pm 4.1$ \\
9-OH-10-Methylated derivative & \\
\hline
\end{tabular}

* Values are mean $\pm \mathrm{sd} ; n \geq 3$.

tion of either the 9-OH $\left(\mathrm{R}_{1}\right)$ or the 10-OH group $\left(\mathrm{R}_{2}\right)$, and both $9,10-\mathrm{OH}$ groups $\left(\mathrm{R}_{1}, \mathrm{R}_{2}\right)$ in paepalantine 1 reduced cytotoxicity. All compounds gave a significant cytotoxic index when compared to the $\mathrm{IC}_{50}$ value of cisplatin $(41.9 \pm 5.2 \mu \mathrm{g} / \mathrm{ml})$ used as the reference compound.

For coumarins, generally the in vitro structureactivity relationship studies have shown that cytotoxicity is found only with derivatives containing ortho-dihydroxy substituents (Kolodziej et al., 1997). The higher cytotoxicity of paepalantine 1 compared with the other isocoumarins in this study seems to be related to the $\mathrm{OH}-9$ and $\mathrm{OH}-$ 10 groups, since they provide a cathecolic-like system.

The chemical structure/biological activity study of the coumarins showed that the addition of a cathecolic group to the basic structure induces increased cytotoxic activity in tumor cell lines (Kolodziej et al., 1997). Paepalantine 1 has hydroxyls at positions 9 and 10 of the aromatic ring, making it similar to a cathecolic system. Based on our results, the substitutions of the free hydroxyls at positions 9 and/or 10 reduced the cytotoxicity of the isocoumarins.

The different cytotoxic values found for the isocoumarins could be related to presence and the positions of the hydroxyls in their structures. The groups found at positions 1,9 and 10 of paepalantine 1 permitted the formation of two intramolecu- lar hydrogen bridges, making this molecule more lipophilic than the other isocoumarins in this study. The substitution of the free hydroxyl at position 9 of paepalantine 1 by other chemical groups resulted in the formation of only one hydrogen bridge between positions 1 and 10, reducing the hydrophobicity of the new substances (paepalantine-9-O- $\beta$-D-glucopyranoside and paepalantine-9-O- $\beta$-D-allopyranosyl $(1 \rightarrow 6)$ glucopyranoside). Cathecolic systems should also be capable of forming intramolecular hydrogen bridges. The 9-OH-10 methylated derivative has a substitution at position 10, which impedes formation of the intramolecular hydrogen bridge, and therefore, theoretically, would by less hydrophobic, when compared to paepalantine 1 .

Observations concerning the lipophylic nature of these compounds were confirmed by comparative thin layer chromatography. Another aspect was the simultaneous substitution of the $\mathrm{OH}$ groups at position 9 and 10 (9,10-acylated derivative), which impedes the formation of intramolecular links. Nevertheless, chromatography shows that this derivative is slightly less lipophylic than paepalantine 1 . Paepalantine-9-O- $\beta$-D-glucopyranoside and paepalantine-9-O- $\beta$-D-allopyranosyl $(1 \rightarrow 6)$ glucopyranoside are less lipophylic than paepalantine 1 , which could be due to their glycolyzed radicals.

The isocoumarins we studied have diverse biological properties and various effects on the different cellular systems. Other biological parameters should be evaluated to increase our understanding of mechanisms by which these isocoumarins act.

\section{Acknowledgements}

We thank FAPESP for a grant given to K. F. D, CNPq for a fellowship for W. V. and PADCUNESP for providing financial assistance to M. S. G. R. 
Bacon J. A., Linseman D. A. and Raczniak T. J. (1990), In vitro cytotoxicity of tetracyclines and aminoglycosides in LLC-PK, MDCK and Chang continuous cell lines. Toxic in vitro 4, 384-388.

Balls M. and Clothier R. (1992), Cytotoxicity assays for intrinsic toxicity an irritancy. In: In vitro Methods of Toxicology (Watson R. R., ed.). CRC Press, Boca Raton, 37-52.

Barile F. A. (1994), Introduction to in vitro Cytotoxicology: Mechanisms and Methods. CRC Press, Boca Raton.

Borenfreund E. and Puerner J. A. (1985), Toxicity determined in vitro by morphological alterations and neutral red absorption. Toxicol. Lett. 24, 119-24.

Cañedo L. M., Puents J. L. F. and Baz J. P. (1997), PM94128, a new isocoumarin antitumor agent produced by a marine bacterium. J. Antibiotics 50, 175-176.

Freshney R. I. (1994), Culture of animal cells: a manual of basic technique, 3ed, Wiley, New York.

Hill R. A. (1986), Naturally occurring isocoumarins. Chem Org. Naturst. Fortschr. 49, 1-78.

Ishiyama M., Tominaga H., Masanobu S., Sasamoto K., Ohkura Y. and Ueno K. (1996), A combined assay of cell viability and in vitro cytotoxicity with a highly water-soluble tetrazolium salt, neutral red and crystal violet. Biol Pharm. Bull. 19, 1518-1520.

Kolodziej H., Kayser O., Woedenbag H. J., Van Uden W. and Pras N. (1997), Structure-cytotoxicity relationships of a series of natural and semi-synthethic simple coumarins as assessed in two human tumor cell lines. Z. Naturforsch. 52c, 240-244.
Lake, B. G. (1999), Coumarin metabolism, toxicity and carcinogenicity: relevance for human risk assessment. Food Chem. Toxicol. 37, 423-453.

Tavares D. C., Varanda E. A., Andrade F. D., Vilegas W. and Takahashi C. S. (1999), Evaluation of the genotoxic potential of the isocoumarin paepalantine in in vivo and in vitro mammalian systems. J. Ethnopharmacol. 68, 115-120.

Varanda E. A., Raddi M. S. G., Dias F. L., Araujo M. C. P., Gibran S. C. A., Takahashi C. S. and Vilegas W. (1997), Mutagenic and cytotoxic activity of an isocoumarin (paepalantine) isolated from Paepalanthus vellozioides. Terat. Car. Mutat. 17, 85-95.

Vilegas W., Santos L. C., Alécio A. C., Pizza C., Piacente S., Pauw E. D. and Sano P. T. (1998), Naphthopyranone glycosides from Paepalanthus bromelioides. Phytochemistry 49, 207-210.

Vilegas W., Roque N. F., Salantino A., Giesbrecht A. M. and Davino S. (1990), Isocoumarin from Paepalanthus bromelioides. Phytochemistry 29, 2299-2301.

Whyte A. C., Gloer J. B., Scott J. A. and Malloch D. (1996), Cercophorins A-C: Novel antifungal and cytotoxic metabolites from the coprophilus fungus Cercophora areolata. J. Nat. Prod. 59, 765-769.

Zepink H., Pahler A., Schauer U. and Dekant W. (2001), Ochratoxin A-induced tumor formation: is there a role of reactive ochratoxin A metabolites? Toxin Sci. 59, 59-67. 